\title{
Myxopapillary Ependymoma of the III Ventricle: Example of a Histological Variant of Ependymoma with Exceptional Localization
}

\author{
J. Ortiz ${ }^{*}$, , L. Chinchilla, E. Muñoz, Md. Ludeña \\ Department of Pathology, University Hospital of Salamanca, Salamanca, Spain \\ Email: ${ }^{* j o r t i z @ u s a l . e s ~}$
}

How to cite this paper: Ortiz, J., Chinchilla, L., Muñoz, E. and Ludeña, Md. (2020) Myxopapillary Ependymoma of the III Ventricle: Example of a Histological Variant of Ependymoma with Exceptional Localization. Open Journal of Pathology, 10, 51-55.

https://doi.org/10.4236/ojpathology.2020.1 $\underline{01005}$

Received: November 1, 2019

Accepted: January 7, 2020

Published: January 10, 2020

Copyright $\odot 2020$ by author(s) and Scientific Research Publishing Inc. This work is licensed under the Creative Commons Attribution International License (CC BY 4.0).

http://creativecommons.org/licenses/by/4.0/

\section{(c) (i) Open Access}

\begin{abstract}
We present morphological findings observed from the study of a myxopapillary ependymoma located in the III ventricle. This tumor, which is a rare occurrence at this level, was observed in a 73-year-old woman with no relevant medical history who presented with obstructive hydrocephalus due to compression and blockage of the foramen of Monro. The good delineation of the lesion allowed its surgical excision, and histological examination of the material obtained after excisional biopsy revealed a glial neoplasm with a low degree of cytological malignancy that was strongly positive for glial fibrillary acidic protein (GFAP) as well as a myxopapillary architecture analogous to that observed in ependymomas of the filum terminale. Subsequent radiological examination allowed us to rule out a metastatic nature of the tumor, confirming its primary origin. We briefly discuss the case and review the main characteristics of this neoplasia, which is quite rare at the site identified in our patient.
\end{abstract}

\section{Keywords}

Myxopapillary Ependymoma, III Ventricle, Immunohistochemistry

\section{Introduction}

A papillary architecture, a loose stroma rich in acidic mucopolysaccharides and cellularity with a benign appearance positive for glial markers (GFAP) are the main histological and immunohistochemical features that define myxopapillary ependymoma, a variant of ependymal tumors recognized in all clinical/pathological classifications [1] [2] [3]. This lesion, which is considered a grade I tumor by the WHO, presents less aggressive clinical behavior than the remaining ependymo- 
mas included by the WHO in the groups of grade II tumors (classical ependymoma and its histological variants) and grade III tumors (anaplastic ependymoma) [4] [5]. Most cases are characteristically located at the level of the filum terminale, with very few intra-axial tumors observed outside of this location [6] [7]. Nonetheless, examples of extra-axial myxopapillary ependymoma have been described, including tumors of the sacrococcygeal and lumbar regions [8] [9].

In our report, we present a myxopapillary ependymoma of the III ventricle, which is an exceptional location for this type of lesion and has not yet been almost described in the medical literature [10].

\section{Case Report}

A 73-year-old woman with no relevant medical history visited our hospital due to progressive symptoms of obstructive hydrocephalus with headache, projectile vomiting and progressive deterioration of consciousness. Physical examination showed discrete optic disc edema, and radiological examination (magnetic resonance imaging (MRI)) revealed of a tumor located in the III ventricle (posterior hypothalamic area) with a maximum diameter of $3.5 \mathrm{~cm}$, good delineation and no signs of pathological vascularization, which compressed the foramen of Monro, causing dilatation of the left lateral ventricle (Figure 1). Excisional biopsy of the tumor yielded a grayish material with a soft consistency and loose appearance throughout its entirety in the histological examination. This examination revealed a focally cystic myxoid neoplasm with papillary areas consisting of uniform cells with a benign appearance (Figure 2(a) and Figure 2(b)). No abnormal vessels or necrotic foci were observed. Immunohistochemical analysis (Figure 3 ) showed that the tumor cells exhibited strong positivity for glial fibrillary acidic protein (GFAP) but negativity for cytokeratins (CAM 5.2, AE1-AE3), IDH1, synaptophysin, enolase and p53. The proliferative index (Ki67) was less than $1 \%$.

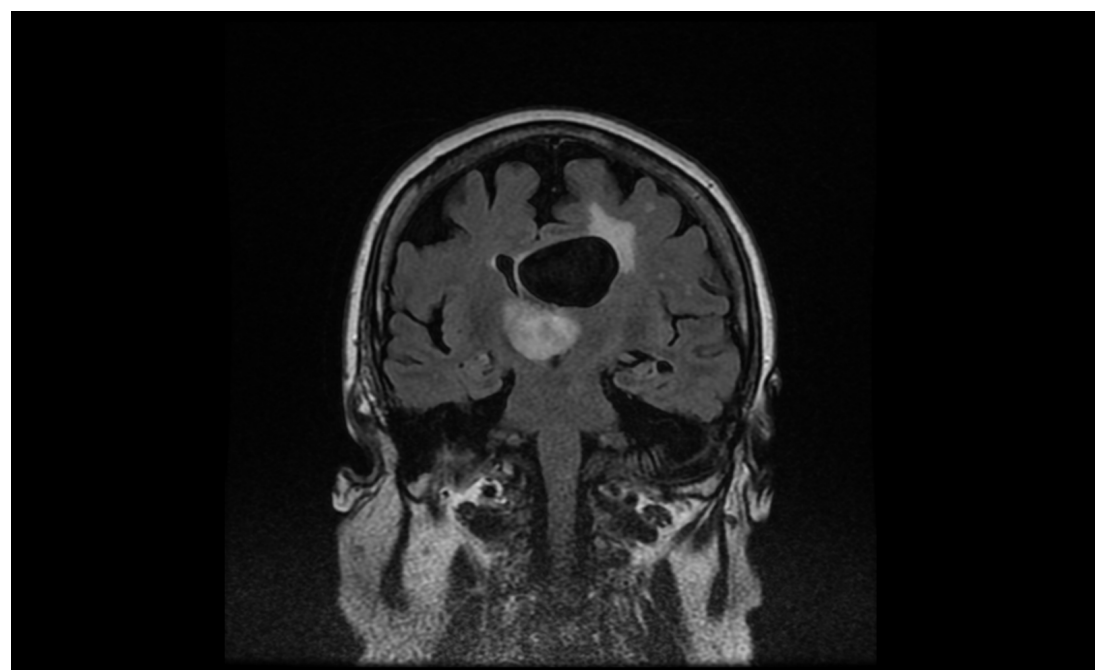

Figure 1. An intraventricular tumor occupying the III ventricle, obstructing the foramen of Monro and causing dilatation of the left lateral ventricle (MRI T2/FLAIR). 


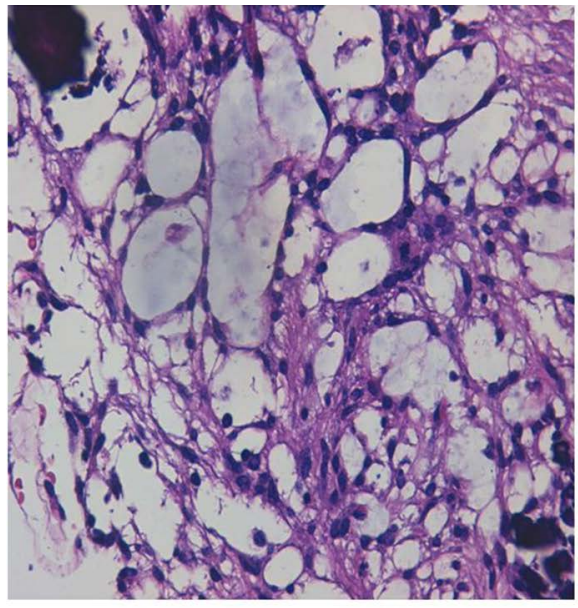

(a)

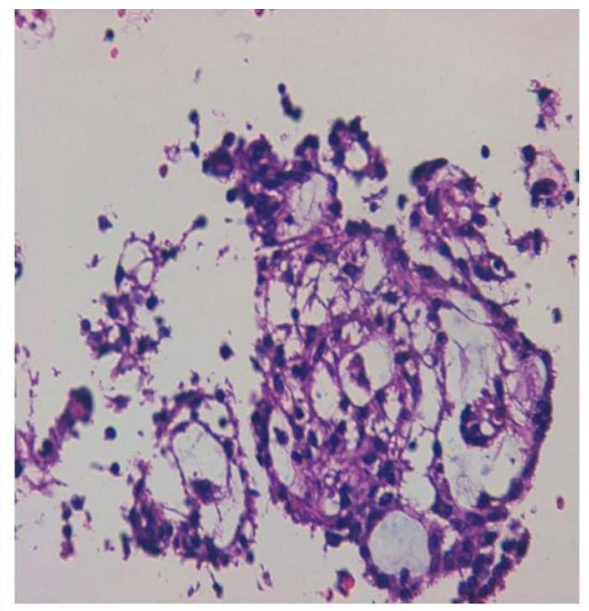

(b)

Figure 2. (a) Myxopapillary ependymoma: A tumor with multiple myxoid microcystic areas (HE $\times 200)$; (b) Myxopapillary ependymoma: myxoid papillary areas $(\mathrm{HE} \times 100)$.

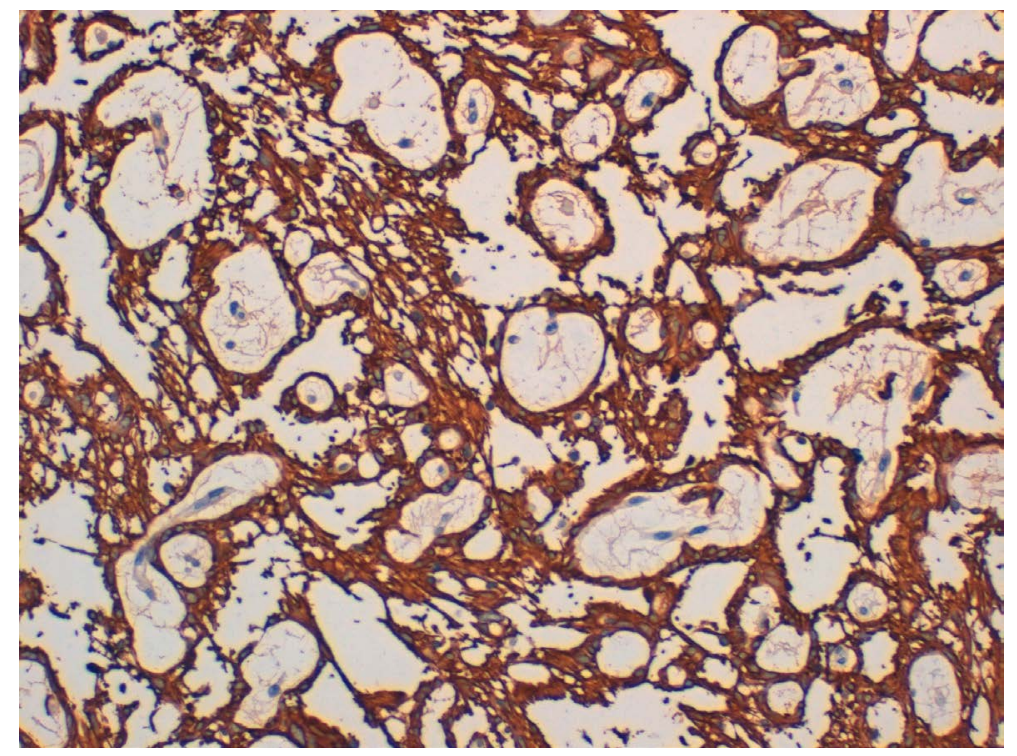

Figure 3. Myxopapillary ependymoma: tumor positivity for GFAP $(\mathrm{IHC} \times 100)$.

Based on these data, we established a diagnosis of myxopapillary ependymoma and ruled out a metastatic nature after radiological examinations (MRI and CT scans), which confirmed the absence of lesions in the cauda equina and filum terminale.

Two years after her surgical treatment, the patient shows a good general condition, without clinical or radiological signs of tumor recurrence.

\section{Discussion}

Pathological diagnosis, which is based primarily on the histological study of lesions, involves correlating the histology of a lesion with the clinical data of the patient and with other morphological parameters (macroscopic and radiological appearance) to establish a prognosis and possible treatment. 
This statement, which is a key element of our anatomoclinical mentality, indicates that when determining a diagnosis, all pathologists value elements such as the patient's clinical history, the lesion site and its macroscopic and radiological appearance. Currently, histological studies are complemented with modern immunohistochemistry, molecular biology and occasionally, electron microscopy techniques, the pillars on which our decisions must be based.

Therefore, we consider the case reported here to be of interest: a myxopapillary ependymoma with exceptional localization. The tumor, which had a morphology compatible with previously described cases, required us to establish a differential diagnosis with other entities. Thus, the negativity for epithelial markers (CAM5.2 and cytokeratins AE1-AE3) and the positivity for GFAP allowed us to exclude the possibility of a metastatic carcinoma. Similarly, the radiological examinations allowed us to rule out the possibility of dissemination of an intra-axial tumor through the cerebrospinal fluid [11] [12]. These previously described facts allow us to confirm the myxopapillary character of the tumor, and its intraventricular primary origin (third ventricle), which makes it different from other cerebral ependymal neoplasms recently described, which either presented different histological pattern or their location was different from the one observed in our case [13] [14] [15].

Finally, remember, again, the good evolution observed in the patient in these two years, which reaffirms our diagnosis, and highlights, once again, the importance of collaboration between clinicians, radiologists and pathologists, a key element of good work welfare.

\section{Conflicts of Interest}

The authors declare no conflicts of interest regarding the publication of this paper.

\section{References}

[1] Kleihues, P., Louis, D.N., Scheithauer, B.W., Rorke, L.B., Reifenberger, G., Burger, P.C. and Cavenee, W.K. (2002) The WHO Classification of Tumors of the Nervous System. Journal of Neuropathology \& Experimental Neurology, 61, 215-225. https://doi.org/10.1093/jnen/61.3.215

[2] Louis, D.N., Ohgaki, H., Wiestler, O.D., Cavenee, W.K., Burger, P.C., Jouvet, A., Scheithauer, B.W. and Kleihues, P. (2007) The 2007 WHO Classification of Tumours of the Central Nervous System. Acta Neuropathologica, 114, 97-109. https://doi.org/10.1007/s00401-007-0243-4

[3] Louis, D.N., Perry, A., Burger, P., Ellison, D.W., Reifenberger, G., von Deimling, A., Aldape, K., Brat, D., Collins, V.P., Eberhart, C., Figarella-Branger, D., Fuller, G.N., Giangaspero, F., Giannini, C., Hawkins, C., Kleihues, P., Korshunov, A., Kros, J.M., Beatriz Lopes, M., Ng, H.K., Ohgaki, H., Paulus, W., Pietsch, T., Rosenblum, M., Rushing, E., Soylemezoglu, F., Wiestler, O. and Wesseling, P. (2014) International Society of Neuropathology-Haarlem Consensus Guidelines for Nervous System Tumor Classification and Grading. Brain Pathology, 24, 429-435.

https://doi.org/10.1111/bpa.12171 
[4] Hübner, J.M., Kool, M., Pfister, S.M. and Pajtler, K.W. (2018) Epidemiology, Molecular Classification and WHO Grading of Ependymoma. Journal of Neurosurgical Sciences, 62, 46-50.

[5] Gerstner, E.R. and Pajtler, K.W. (2018) Ependymoma. Seminars in Neurology, 38, 104-111. https://doi.org/10.1055/s-0038-1636503

[6] Chakraborti, S., Govindan, A., Alapatt, J.P., Radhakrishnan, M. and Santosh, V. (2012) Primary Myxopapillary Ependymoma of the Fourth Ventricle with Cartilaginous Metaplasia: A Case Report and Review of the Literature. Brain Tumor Pathology, 29, 25-30. https://doi.org/10.1007/s10014-011-0059-8

[7] Khalatbari, M.R. and Moharamzad, Y. (2014) Primary Cerebral Myxopapillary Ependymoma Presenting with Intratumoral Hemorrhage. British Journal of Neurosurgery, 28, 523-524. https://doi.org/10.3109/02688697.2013.859656

[8] Shelekhova, K.V., Egorenkov, V.V., Kheinstein, V.A., Konstantinova, A.M., Iyevleva, A., Imyanitov, E.N., Matsko, M.V. and Matsko, D.E. (2018) Myxopapillary Ependymoma of Lumbar Soft Tissue: A Case Report with Gene Expression Evaluation. International Journal of Surgical Pathology, 26, 364-369. https://doi.org/10.1177/1066896917748195

[9] Schiavello, E., Biassoni, V., Antonelli, M., Modena, P., Cesaro, S., Pierani, P. and Gandola, L. (2018) Pediatric Extraspinal Sacrococcygeal Ependymoma (ESE): An Italian AIEOP Experience of Six Cases and Literature Review. Child s Nervous System, 34, 1291-1298. https://doi.org/10.1007/s00381-018-3805-y

[10] Wang, M., Wang, H., Zhou, Y., Zhan, R. and Wan, S. (2013) Myxopapillary Ependymoma in the Third Ventricle Area and Sacral Canal: Dropped or Retrograde Metastasis? Neurologia Medico-Chirurgica, 53, 237-241. https://doi.org/10.2176/nmc.53.237

[11] Fonseca, L., Cicuendez, M., Martínez-Ricarte, F., Martínez-Saez, E., Cordero, E. and Bescos, A. (2019) A Rare Case of an Intramedullary Metastasis of a Myxopapillary Ependymoma. Surgical Neurology International, 10, 83. https://doi.org/10.25259/SNI-96-2019

[12] Kraetzig, T., McLaughlin, L., Bilsky, M.H. and Laufer, I. (2018) Metastases of Spinal Myxopapillary Ependymoma: Unique Characteristics and Clinical Management. Journal of Neurosurgery Spine, 28, 201-208. https://doi.org/10.3171/2017.5.SPINE161164

[13] Prat-Acín, R., Evangelista, R., Conde, R., Ayuso-Sacido, A. and Galeano, I. (2017) Neuroendoscopic Management of Posterior Third Ventricle Ependymoma with Intraaqueductal and Fourth Ventricle Extension: A Case Report and Review of the Literature. Child s Nervous System, 33, 2057-2060.

https://doi.org/10.1007/s00381-017-3543-6

[14] Takami, H., Graffeo, C.S., Perry, A., Raghunathan, A., Jenkins, R.B., Giannini, C. and Burns, T.C. (2017) Giant Cell Ependymoma of Lateral Ventricle: Case Report, Literature Review, and Analysis of Prognostic Factors and Genetic Profile. World Neurosurgery, 108, 997.e9-997.e14. https://doi.org/10.1016/j.wneu.2017.09.088

[15] Choque-Velasquez, J. and Hernesniemi, J. (2018) Unedited Microneurosurgery of a Pineal Region Ependymoma. Surgical Neurology International, 9, 260. 